\title{
COMPLICAÇÕES APÓS APLICAÇÕES, POR VIA INTRAMUS- CULAR, DO DICLOFENACO DE SÓDIO: ESTUDO DE UM CASO
}

\author{
INTRAMUSCULAR SITE COMPLICATIONS AFTER SODIUM DICLOFENAC INJECTIONS: CASE RELATED
}

Silvia H. B. Cassiani' ${ }^{1}$ Silvia M. Rangel², Francisco Tiago ${ }^{3}$

\begin{abstract}
${ }^{1}$ Docente do Departamento de Enfermagem Geral e Especializada; ${ }^{2}$ Aluna do 6o semestre de graduação; Escola de Enfermagem de Ribeirão Preto da Universidade de São Paulo. ${ }^{3}$ Técnico de Enfermagem do Centro de Saúde Escola da Universidade de São Paulo de Ribeirão Preto.

CorResPondênCIA: Prof ${ }^{a}$ Dr ${ }^{a}$ Silvia H. B. Cassiani. Avenida dos Bandeirantes, 3900 - Ribeirão Preto - SP - Cep: 14040-902 - Fax: (016) 602 3453. E-mail: shbcassi@glete.eerp.usp.br.
\end{abstract}

CASSIANI SHB; RANGEL SM \& TIAGO F. Complicações após aplicações, por via intramuscular, do Diclofenaco de Sódio: estudo de um caso. Medicina, Ribeirão Preto, 31: 99-105, jan./mar. 1998.

RESUMO: O uso da injeção intramuscular na terapêutica medicamentosa envolve, na atualidade, uma série de aspectos como: desvantagens quanto ao local, reações adversas e complicações surgidas após as injeções. Este estudo tem o objetivo de relatar o caso de uma paciente com complicações pós-aplicação de dezoito injeções de Diclofenaco de Sódio. As complicações apresentadas foram dermatológicas e musculares. Ao final, são discutidos cuidados a serem tomados na aplicação de injeções intramusculares, em especial, no uso de Diclofenaco de Sódio, a fim de se evitarem mais casos de complicações, após administração de medicações por via intramuscular.

UNITERMOS: Injeções Intramusculares. Enfermagem. Diclofenaco de Sódio.

\section{INTRODUÇÃO}

A injeção é o meio utilizado para a introdução de medicamentos por via parenteral. O primeiro registro publicado, descrevendo a administração de uma substância com seringa e agulha, é datado de 1955 e foi descrito por Alexander Wood, de Edimburgo, relatando a eficiência da injeção de uma solução de morfina na via subcutânea, para produzir alívio imediato da dor. Entretanto, as drogas são administradas por injeção intramuscular há mais de um século.

Aproximadamente em 1945, o emprego da via intramuscular era comum, sendo que os médicos eram cuidadosamente treinados na aplicação de injeções intramusculares, nas clínicas para tratamento da sífilis, requerendo-se deles, uma técnica cuidadosa a fim de evitarem lesões ao organismo humano. Essa via de administração é habitualmente utilizada, quando a doença do paciente ou a propriedade farmacocinética da droga impede o seu uso por via oral ${ }^{(1)}$.

Entretanto, vários estudos indicam que as injeções intramusculares têm desvantagens que devem ser consideradas, como formação de abscesso, eritema, infiltrações no tecido subcutâneo, embolias e lesões nervosas $^{(2,3,4,5)}$. Outras complicações relatadas são: dor violenta, com irradiação ou não, durante ou imediatamente após a aplicação do medicamento, rubor, hematomas, nódulos, paresias, paralisias ou necrose.

GREENBLAT \& ALLEN $(1978)^{(2)}$, em um estudo, acompanhando doze mil, cento e trinta e quatro pacientes que receberam, ao menos, uma injeção intramuscular, observaram, em quarenta e oito pacientes $(0,4 \%)$, reações adversas, atribuídas à injeção, sendo que, em trinta e três pacientes, tais reações foram registradas após dois dias do início da terapia. As reações encontradas foram: formação de abscesso no 
local da injeção, em quinze pacientes; endurecimento local e dor persistente em onze casos, formação de hematomas, sangramento e nódulo permanente em seis, três e dois casos, respectivamente. Em nenhum caso, as complicações locais foram consideradas graves, mas as reações adversas interromperam a terapia em vinte e dois casos.

Em nosso meio, não é muito freqüente as pessoas retornarem aos serviços de saúde com queixas relativas às complicações nos sítios das injeções. Percebemos que, em muitos casos, as pessoas creditam a dor excessiva, o abscesso e o hematoma à própria medicação injetada, como se essas reações fossem comuns em qualquer injeção. Queixam-se para familiares e amigos da falta de habilidade do funcionário que administrou, seja ele da enfermagem ou da farmácia, e tomam medidas terapêuticas, no próprio domicílio, para alívio da dor, como uso de pomadas, calor local ou aumento dos movimentos. Muitas vezes, são orientadas, no próprio serviço onde receberam a injeção, sobre os cuidados que devem ter no sítio da injeção e que são, basicamente, os mesmos citados acima.

Todavia, o Serviço de Saúde só toma conhecimento de alguns casos, quando as complicações se tornam graves ou já estão em estado avançado, como necroses ou abscessos após várias injeções. Vale considerar que, nem sempre, esse serviço é o mesmo onde as injeções foram administradas, e, assim, nenhuma medida é tomada, quando a falha é técnica, como reciclagem, atualização de conhecimentos ou educação continuada dos funcionários.

Casos isolados, porém significativos, de pacientes, apresentando complicações pós-administração intramuscular de vários medicamentos, chamou-nos a atenção, especificamente o caso de uma paciente com vários comprometimentos musculares. Então, decidimos, por meio deste estudo, relatar o caso de uma paciente que apresentou reações após receber dezoito (18) injeções de Diclofenaco de Sódio por via intramuscular. Acreditamos, assim, que, este estudo, possa contribuir na compreensão das causas, complicações e reações pós-injeções intramusculares em adultos.

Há de se ressaltar a propriedade e a adequação da metodologia de estudo de caso à temática proposta. Observa-se que ela é uma das metodologias empregadas nos vários estudos sobre complicações pós-injeções intramusculares, visto que os casos raros devem ser analisados em profundidade, a fim de que essas situações possam ser prevenidas em futuros momentos ${ }^{(6)}$.
Acrescenta-se, ainda, que há pouca informação definida sobre a freqüência de reações adversas em injeções intramusculares. Complicações sérias são raras e podem ser descritas sob a forma de estudos de caso, já que aparecem isoladamente ${ }^{1}$.

\section{OBJETIVO}

Este estudo tem, portanto, o objetivo de relatar o caso de uma paciente com complicações após administração de dezoito ampolas de Diclofenaco de Sódio (D.S) por via intramuscular.

\section{PROCEDIMENTOS PARA A COLETA DE DADOS}

A paciente procurou o Serviço de Saúde, apresentando úlcera varicosa no membro inferior direito e requerendo curativo da mesma. Relatou que vinha apresentando outra lesão na região do músculo ventroglúteo direito, conseqüente a aplicações de injeções. A partir dessa informação, foram coletados dados de identificação, história clínica e exame físico dos sítios das injeções.

Para tanto, a paciente foi informada acerca dos objetivos do estudo e foi solicitado seu consentimento para a realização das entrevistas e obtenção das fotografias do local das aplicações de injeções.

A entrevista foi realizada no domicílio da paciente, acompanhada por informações da filha. A entrevista foi gravada e posteriormente transcrita. Além da entrevista, fotos dos vários locais que apresentam as complicações, foram tiradas, para documentar as possíveis lesões à pele, causadas pelas múltiplas aplicações de injeções intramusculares.

\section{RELATO DO CASO}

M.A .S, 39 anos, do sexo feminino, negra, procurou o serviço para a realização de curativo em úlcera varicosa no MID. A paciente relatou vários problemas de saúde como: lúpus eritematoso, cálculo renal, úlcera varicosa, trombose no membro inferior direito e problemas pulmonares. Já realizou vários tipos de tratamento prévios para a doença de base e para as doenças subjacentes.

Ao iniciar o tratamento de saúde, no atual serviço, foi diagnosticado um problema relativo às injeções anteriormente recebidas.

$\mathrm{Na}$ cidade onde residia anteriormente, foi medicada diversas vezes com Diclofenaco de Sódio. Sentia fortes dores nas articulações e nos MMII devido à 
trombose, e era medicada todo dia com duas a três injeções intramusculares, deste medicamento. Em alguns dias de dores intensas, recebeu até seis injeções. Em momentos de dor intensa, se auto aplicava ou alguém da família o fazia, já que tinha a medicação dentro de casa. Entretanto, nem a paciente nem nenhum familiar tem conhecimento do procedimento técnico de aplicação de injeções intramusculares. Recebia as injeções tão freqüentemente que era difícil fazer a escolha de um lugar que não apresentasse hematomas, nódulos ou abcessos. Relata que, nas horas de desespero, quando chegava ao Pronto Socorro ou no plantão noturno de Hospital Filantrópico, os profissionais de saúde aplicavam "em qualquer lugar”, já que não tinha, no corpo, mais nenhum lugar apropriado para receber injeções, porque já havia recebido outras injeções de Penicilina Benzatina, anteriormente ao Diclofenaco de Sódio.

Como resultado dessas aplicações, primeiramente surgiram reações adversas nos músculos deltóides, esquerdo e direito, há dois anos. Notou uma forte dor no sítio da injeção imediatamente após a administração, vinte e quatro horas depois, havia um hematoma no lugar e, após alguns dias, uma lesão, envolvendo pele e tecido muscular. Informou que a lesão era de tão "grande extensão" que não conseguia movimentar o membro superior, mas cicatrizou sem cuidados específicos. Usou "VicVaporub" e outros produtos. Ao exame físico atual, notaram-se lesões cicatrizantes nos músculos deltóides, direito e esquerdo, dorso glúteo direito e esquerdo, vasto lateral esquerdo e face interna anterior da coxa com pele retraída e endurecimento no local, à palpação.

No deltóide esquerdo, a afeção ocupa quase todo o músculo, há vários nódulos e depressões dispersas no local, que demonstram perda de massa muscular; no lado direito, a lesão é semelhante, porém em menor extensão. Neste local, decorreram de dois a três meses para a cicatrização total.

No músculo anterolateral da coxa, tanto do MID como MIE, a paciente relata que apareceram, no mesmo dia da aplicação, ardor, uma mancha escurecida e, no dia seguinte, dores, e princípio de um endurecimento local, que culminou em lesão necrótica e infecção. Apresenta no lado direito uma massa endurecida de formato circular, de cerca de $3 \mathrm{~cm}$ de diâmetro, com cicatriz no local onde foi introduzida a injeção. No lado esquerdo, há uma cicatrização decorrente, segundo a paciente, de uma auto-aplicação, que apresenta cicatriz deprimida, semelhante à descrita ante- riormente, porém não apresentou problemas de movimentação durante a evolução da reação.

As injeções foram também aplicadas na região glútea ("foram mais de uma"), há cerca de sete meses. Ao exame físico, nota-se, no quadrante superior, externo, esquerdo, uma lesão acometendo pele, tecido subcutâneo e muscular, com formato irregular, não ocluída, úmida, sem secreção purulenta, e a área ao redor apresenta-se endurecida e edemaciada. Relata que essa lesão, no início, ficou semelhante a um tumor, com um inchaço local com características de uma inflamação, disse que um líquido claro escorria do local, constantemente, e não conseguia apoiar o pé esquerdo no solo devido a forte dor em pontada, que iniciava no pé e terminava no glúteo; algumas vezes, sentia a "perna" sem reflexos de movimentação, e era preciso apoio para caminhar, a coxa ficou muito edemaciada. Nessa ocasião, procurou o Serviço de Saúde para tratamento e início da limpeza do local com soro fisiológico e, depois, aplicação tópica de Neomicina.

Relatou que os médicos temiam que necessitasse de cirurgia ou viesse a perder a movimentação da "perna”. Não foi possível a movimentação do membro por três meses, sendo que, nesse período, a paciente permanecia a maior parte do tempo na cama, movendo-se o mínimo possível. Relatou que: "me incomodava muito, o músculo aqui na perna parece que ficou todo solto, quando mexia podia ver tudo por dentro da ferida".

Na nádega direita, também há uma cicatrização, na região mediana, com a presença de hematoma local e nodulação.

Atualmente, a paciente faz uso de Diclofenaco de Sódio por via oral. Informou que não tomou outra medicação no período, e que muitas aplicações foram feitas sempre no mesmo lugar, e só se passava para outro local, quando surgia alguma reação. Queixou-se de dor nas injeções. Relata alergia a Furacim. Não procurou serviços de saúde para o tratamento das complicações decorrentes das aplicações, mas passava qualquer produto que tivesse em casa.

Atualmente o único dos locais possíveis de receber injeções e que não apresenta complicações é o ventroglúteo direito.

Informou que a prescrição do médico era sempre a aplicação intramuscular do Diclofenaco de Sódio e que este aliviava a dor, razão pela qual procurava sempre por esse medicamento, tendo inclusive ampolas em seu domicílio. No total, foram dezoito injeções de Diclofenaco de Sódio, no período de três meses. 


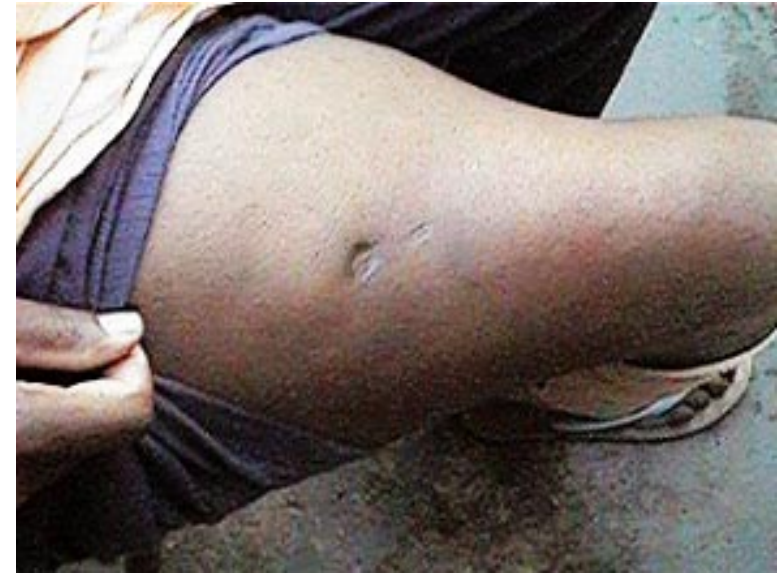

Figura 1

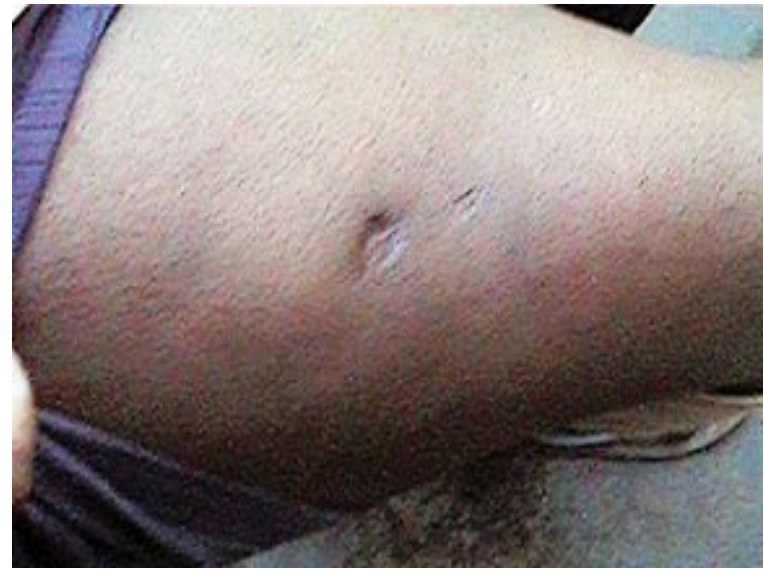

Figura 2

Figuras 1 e 2 - Região da coxa - auto-aplicação de Diclofenaco de Sódio.

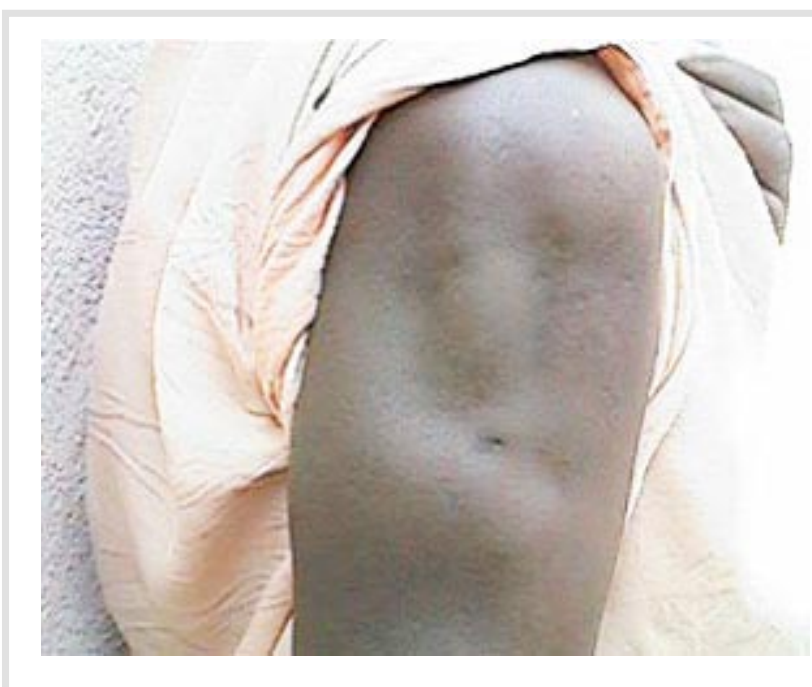

Figura 3 - Região do Deltóide - MSD.

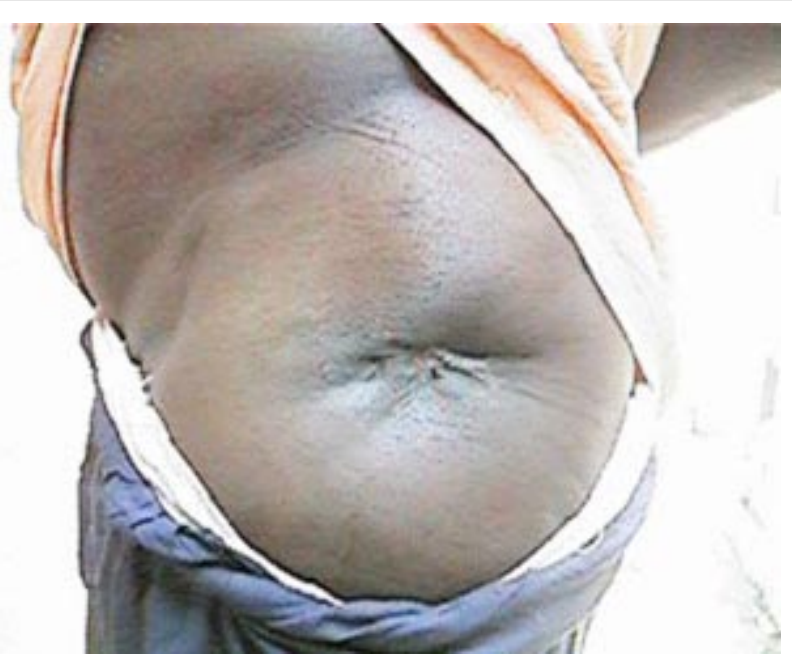

Figura 4 - Região Ventroglútea

\section{DISCUSSÃO}

$\mathrm{Na}$ literatura, encontramos vários artigos com relatos de casos de complicações, após injeções de Diclofenaco de Sódio, que apresentam notável semelhança com o relatado neste estudo.

O Diclofenaco de Sódio é um antiinflamatório não hormonal, existente desde 1974. É amplamente utilizado como analgésico e antiinflamatório no tratamento de doenças reumáticas, pós-operatórias, cólicas, biliar e renal, traumas ortopédicos e dismenorréia. Tem também um potente efeito antipirético. É usado mundialmente, e estima-se que, num período de quatro anos, cerca de dez milhões de pacientes fizeram uso da droga ${ }^{(7,8)}$.
Os autores citados acima são unânimes em afirmar serem poucos os casos de reações adversas, quando se considera a quantidade de injeções intramusculares ministradas à população, e também quanto à gravidade das conseqüências.

A posologia é uma ampola de $75 \mathrm{mg}(3 \mathrm{ml})$ por dia, injetada profundamente no quadrante superior, externo, da região glútea, sendo que, excepcionalmente, injeções separadas por intervalos de algumas horas podem ser administradas por dia (uma em cada nádega). Por se tratar de medicação para situações agudas e de crise, não é recomendado para tratamento com duração superior a dois dias.

Segundo GOLEMAN et al.(1991) ${ }^{(7)}$ o Diclofenaco de Sódio apresenta boa tolerabilidade, sendo raros 
os efeitos colaterais graves. Os efeitos colaterais mais freqüentemente associados ao seu uso envolvem o trato gastrointestinal e regridem com a suspensão da droga, e os efeitos cutâneos mais comuns são exantema e urticária.

GIOVANNETTI et al.(1993) ${ }^{(8)}$ apresentaram sete casos de pacientes com necrose tecidual nos músculos deltóide e glúteo, após injeção intramuscular de Diclofenaco de Sódio. O objetivo do estudo foi o de alertar para o uso indiscriminado da droga, na via intramuscular, tentando estabelecer critérios para a sua utilização. Dos casos apresentados, há um com quadro de necrose de pele e tecido celular subcutâneo, cerca de vinte dias após a injeção intramuscular no membro superior esquerdo. Em outro caso, o paciente recebeu a medicação na região glútea, esta evoluiu para úlcera, no local da aplicação, e cicatrizou por segunda intenção. São ainda citados outros casos, onde houve necessidade de ressecção de escara seca, enxertia de pele e retirada de parte da musculatura necrosada.

Nesse estudo, há alusão ao fato de que a incidência de trombose diminui, quando o Diclofenaco de Sódio é injetado de forma diluída, e que a pressão e velocidade da injeção poderiam provocar embolia periférica com acometimento de regiões vizinhas. Ainda concluíram que todos os pacientes apresentaram dor durante a aplicação do fármaco, sem que esta fosse descontinuada e, tardiamente, vieram a desenvolver necrose tecidual que, eventualmente se estendia até o plano muscular, necessitando de desbridamento cirúrgico e, ocasionalmente, enxertia de pele ${ }^{(8)}$. E finalizaram, afirmando que o uso indiscriminado do Diclofenaco de Sódio poderá acarretar o aparecimento de um maior número de casos de pacientes com efeitos colaterais.

GOLEMAN et al. (1991) ${ }^{(7)}$ relataram a ocorrência de quatro casos por motivos semelhantes aos anteriores; o primeiro consistiu de uma lesão necrótica de $3 \times 2 \mathrm{~cm}$ de superfície e $3 \mathrm{~cm}$ de profundidade, acometendo pele, tecido celular subcutâneo e parte do músculo glúteo máximo, localizada em nádega direita. A aplicação havia sido realizada há cinquienta e dois dias, para tratamento de cólica renal, e a paciente relatou que fora dolorosa, seguiu-se de aparecimento de um "calombo" azulado e dolorido no local. Foi submetida a desbridamento cirúrgico e curativos diários com soro fisiológico e líquido de Dakin. Cinco meses após a injeção, recebeu alta, apresentando cicatriz deprimida no local, não apresentava déficit motor. No segundo caso, a paciente referiu que tomara uma in- jeção I.M. de Diclofenaco de Sódio na região deltóide, há dois meses, também sentiu dor intensa no músculo, notou aparecimento de coloração azul no local e necrose após alguns dias. A necrose se estendeu até o tecido subcutâneo e, após desbridamento cirúrgico e curativos diários, a paciente recebeu alta, apresentando extensa cicatriz deprimida e discreta retração da pele, sem apresentar déficit motor. O terceiro caso menciona que o paciente, ao receber a terceira injeção da medicação em questão, sentiu um choque no local (deltóide direito) que se estendeu até a ponta dos dedos, causando formigamento transitório. A região foi se tornando enegrecida e ele não conseguia abduzir o braço; foi, então, constatada extensa necrose de pele e de tecido subcutâneo de formato irregular, medindo $15 \times 9 \mathrm{~cm}$. Foi realizado desbridamento cirúrgico, curativos diários, remoção mecânica do tecido desvitalizado, tratamento fisioterápico e enxertia. Após setenta dias da aplicação da injeção, apresentou cicatriz deprimida e importante déficit motor - abdução, reto e anteversão - do membro superior direito. O quarto caso relatado apresentou reações semelhantes às citadas anteriormente, aos quinze dias de evolução, houve drenagem espontânea de pus do deltóide direito. A paciente foi submetida a dois desbridamentos cirúrgicos da necrose cutânea, sendo observado discreto déficit motor (abdução); quarenta e cinco dias após apresentou cicatrização completa com depressão da área afetada e moderado déficit motor.

Também por injeção intramuscular de Diclofenaco de Sódio, ALI \& MATHIAS (1978) ${ }^{(9)}$ expõem três casos de lesão prolongada e formação de abscesso no músculo anterolateral da coxa, resultando em incisão e drenagem, nodulação difusa (calcificação) e cicatriz de $17 \times 7 \mathrm{~cm}$ no local. Citaram o caso de um paciente de sessenta e nove anos, com diabetes, que recebeu injeção intramuscular de Diclofenaco de Sódio no glúteo, começou a apresentar, após quatro dias, arreflexia das pernas e fraqueza muscular nas mesmas. Durante o exame neurológico, referiu persistente dor na espinha lombar, desenvolvendo tetraplegia com insuficiência respiratória após algumas horas. A tomografia computadorizada do pescoço mostrou importante concentração gasosa no canal espinhal e no músculo do mesmo. Os médicos admitiram que bactérias foram introduzidas pela injeção, no músculo glúteo, pois nenhuma outra explicação foi encontrada na necropsia, mas afirmaram também que a existência da diabetes pode ter colaborado para o agravamento do quadro. 
As complicações pós-injeções intramusculares ocorrem, obviamente, com outras medicações além da já citada. Encontra-se, em artigo de THOMAZ \& $\operatorname{BALTAR}(1988)^{(4)}$, um incidente de uma paciente que recebeu Penicilina Benzatina no deltóide direito. Primeiramente, perdeu a noção do sentido, em seguida percebeu perda da sensibilidade na mão e dedos, surgiu uma mancha no local e por todo o membro, além das dores. Os médicos detectaram um quadro de embolia cútis medicamentosa, aliada a embolia periférica e, após vinte e um dias, apresentava lesões necróticas até as últimas falanges. Foi realizada uma "limpeza cirúrgica", preservando as estruturas ósseas, e retirada das polpas digitais; o local cicatrizou totalmente, sem sequielas vasculares ou neurológicas.

FISHER $(1975)^{(10)}$ relata caso semelhante, entretanto, a paciente teve os dedos da mão direita amputados, pois estavam atrofiados e mumificados, depois de quatro semanas da aplicação de Tetraciclina no deltóide.

As injeções intramusculares, por serem um método invasivo, requerem certos cuidados quanto à sua aplicação,como: tipo de medicamento, dose compatível com a estrutura muscular do local de introdução da medicação; idade do paciente; calibre e extensão da agulha e escolha do local da aplicação, que deve priorizar aqueles onde há menor risco de eventuais complicações.

A possível lesão de nervos e vasos sangüíneos pode ser minimizada pela habilidade e conhecimento de quem administra a injeção intramuscular. Segundo ATKINSON \& MURRAY (1989)(11) existem demarcações anatômicas definidas para aplicar injeções e essa técnica exige prática e conhecimentos de Anatomia. A autora menciona quatro áreas preferenciais. A primeira delas é a região ventroglútea, onde não há grandes vasos sangüíneos, nem nervos, e seu tecido adiposo é menos espesso que nas nádegas. A região dorsoglútea que, embora seja um bom local, está próxima do nervo ciático, de grandes vasos sangüíneos e do osso. O músculo vasto lateral, situado na face anterior da coxa, constitui um local seguro, pois não há vasos ou nervos importantes na sua proximidade e, por último, o deltóide que se trata de um músculo pequeno e muito próximo do nervo radial.

GOLEMAN et al (1991) $)^{(7)}$ sugerem que, tendo em vista que acidentes isquêmicos após injeções IM não são raros, e os efeitos podem ser graves e mutilantes, alguns cuidados devem ser tomados no sentido de prevenir sua ocorrência, como: aplicações feitas somente por pessoas que conheçam a técnica, esco- lha adequada do local, dando-se preferência ao músculo glúteo, e aspiração de êmbolo após a introdução da agulha. Entretanto, no Brasil, sabe-se que muitos que aplicam medicamentos via intramuscular nos hospitais, clínicas, farmácias, etc, não têm o necessário, conhecimento teórico e prático que os capacitem para tal atividade.

Observamos, em alguns casos, a aplicação dos medicamentos em locais incorretos, decorrente da má delimitação, e que pode acarretar complicações no local. Portanto, é importante o conhecimento adequado dos passos da técnica de aplicação do medicamento.

No caso específico do caso relatado neste estudo, há evidências atuais que contra-indicam a aplicação do Diclofenaco de Sódio na região deltóide. Entretanto, pudemos observar que a paciente recebeu também injeções neste músculo.

Não temos como atribuir uma causa específica às complicações apresentadas pela paciente, já que temos casos de outros pacientes que apresentaram complicações semelhantes às da paciente, mas não apresentaram a mesma patologia, ou seja, LES; vale ainda ressaltar que, no período das aplicações as injeções, a paciente não estava recebendo nenhum outro medicamento que pudesse facilitar o aparecimento das complicações. Como muitas das injeções foram aplicadas pela própria paciente e familiares, que não têm formação, nem noções da técnica, pode ter havido falhas de assepsia do material e medicamento e inadequação dos procedimentos técnicos.

Temos tido conhecimento de casos de complicações por Diclofenaco de Sódio com pacientes que apresentam diabetes e LES; embora a literatura revele que essas patologias podem agravar as complicações pós-injeções, conhecemos o aparecimento das mesmas complicações em pacientes que não apresentam essas patologias e que receberam apenas uma injeção intramuscular do medicamento em questão.

Cremos que o relato deste caso possa ser analisado junto aos demais existentes e, assim, farmacologistas, farmacêuticos, médicos e enfermeiros, reunidos, possam discutir, em profundidade, as causas dessas complicações sob o ponto de vista de cada área do conhecimento e minimizar o sofrimento causado aos pacientes pela terapêutica.

\section{AGRADECIMENTOS}

Os autores expressam o agradecimento à Fundação de Amparo à Pesquisa do Estado de São Paulo (FAPESP) pelos recursos financeiros recebidos. 
CASSIANI SHB; RANGEL SM \& TIAGO F. Intramuscular site complications after Sodium Diclofenac injections: Case related. Medicina, Ribeirão Preto, 31: 99-105, jan./march 1998.

ABSTRACT: The use of intramuscular injections involves some disadvantages in the site of the injectons as adverse reactions and complications after the injections. This study aims to report a case of a patient with complications after eighteen injections of Diclofenac Sodium. The complications presented were of dermatological level and in the muscles. Authors discussed technical procedures to the administration of injections, specially in the use of the Diclofenac Sodium in order, to minimize cases with complications after intramuscular injections.

UNITERMS: Injections, Intramuscular. Nursing. Sodium Diclofenac.

\section{REFERÊNCIAS BIBLIOGRÁFICAS}

1 - GLEENBLATT OJ \& WESER JK. Intramuscular injetcion of drugs. N Engl J Med 295: 542-546, 1976.

2 - GREENBLATT D \& ALLEN MD. Intramuscular Injection - site complications. JAMA 240: 542-544, 1978.

3 - VALDERRAMA JAF"\& MIGUEL RE. Fibrosis of the gluteus maximus: a cause of limited and adduction of the hep in children. Clin Orthop 156: 67-78,1981.

4 - THOMAZ JB \& BALTAR CAF. Acidente isquêmico no membro superior produzido por injeção intramuscular de penicilina benzatina, Arq Bras Med 62: 1175-1178, 1988.

5 - McIVOR A; PALUZZIM \& MEGUID M. Intramuscular Injection abcess - past lessons relearned. N Engl J Med 324: 18971898, 1991.

6 - GLIEMROTH J; HEISE S \& MISSLER U. A 64 years old man with diabets and ascending paraplegia. Lancet 347: 516, 1996.
7 - GOLEMAN B. et al. Necrose tecidual após injeção intramuscular de Diclofenaco de Sódio - Relato de 4 casos. Rev Bras Dermatol 66: 65-69, 1991.

8 - GIOVANNETTI M et al. Necrose tecidual; efeito colateral do Diclofenaco de Sódio, relato de casos e discussão da fisiopatologia. Rev Hosp Clín Fac Med São Paulo, 48: 3942, 1993.

9 - ALI MT \& MATHIAS JM. Continued problems with diclofenac injections. Anaesthesia, 46: 1089-1090, 1991.

10 - FISHER TL. This proceduree has legal as well as clinical risks. Can Med Assoc J 112: 395-396, 1975.

11 - ATKINSON LD \& MURRAY ME. Fundamentos de enfermagem. Guanabara, Koogan, Rio de Janeiro, 617 p., 1989.

Recebido para publicação em 17/11/97

Aprovado para publicação em 04/03/98 